\title{
A technical and socioeconomic approach to estimate forest residues as a feedstock for bioenergy in northern Mexico
}

\author{
Guadalupe Carrasco-Diaz, Gustavo Perez-Verdin * (D), Jonathan Escobar-Flores and Marco Antonio Marquez-Linares
}

\begin{abstract}
Background: Forest residues can be a feasible alternative for converting energy into fuels, electricity, or heat. Compared to other second-generation bioenergy sources, they do not compete for food, are relatively cheap, abundant in forest-rich areas, and more importantly their energy balance is close to zero. Biomass estimations can help design energy strategies to reduce fossil fuels dependency. Because of the land property distribution in Mexico, biomass estimations should consider not only the physical availability, but also the willingness of landowners to extract such raw materials.
\end{abstract}

Methods: This study presents a methodological approach for evaluating the potential use of forest residues as a feedstock to generate bioenergy in northern Mexico. Remote sensing and field forest inventory were used to estimate the quantity and distribution of forest residues. In addition, a discrete choice analysis evaluated landowners' preferences towards bioenergy development, including the most important factors that influence their willingness to extract their products and the expected price.

Results and conclusions: Considering both physical and socio-economic aspects, results showed that about 59,000 metric tons per year could be available in the study area. The vast majority of landowners surveyed are willing to extract forest residues, as long as they are presented with extraction plans with the highest income. However, many showed concerns about the environmental impacts this activity can have on soils, plants, and fauna. These results can help evaluate the potential of these resources for bioenergy development.

Keywords: Bioenergy, Choice experiments, Forest landowners, Forest residues, Remote sensing

\section{Background}

Bioenergy is the type of renewable energy from biological sources that can be used for heat, electricity fuel, and their co-products (Yuan et al. 2008; Fraver et al. 2018; Rodriguez-Soalleiro et al. 2018). Particularly, plants transforms sunlight into energy during the process of photosynthesis, which eventually becomes the source of our food and fiber (Zhu et al. 2008; Ngugi et al. 2018). Plant biomass can be produced from different sources including agricultural crops and forest biomass. The latter can be separated into components, such as branches, leaves, tops, bark, roots, dried leaves, and dead wood (Schlegel et al. 2000). Through biochemical or physical technologies, this

\footnotetext{
* Correspondence: guperezv@ipn.mx

Instituto Politecnico Nacional, CIIDIR Dgo. Sigma 119, Fracc. 20 de Nov. II., Durango, Mexico
}

Springer Open

(c) The Author(s). 2019 Open Access This article is distributed under the terms of the Creative Commons Attribution 4.0 International License (http://creativecommons.org/licenses/by/4.0/), which permits unrestricted use, distribution, and reproduction in any medium, provided you give appropriate credit to the original author(s) and the source, provide a link to the Creative Commons license, and indicate if changes were made. such as liquid fuels, power, or heat. In Mexico, about 665 Petajoules $(\mathrm{Pj}, 9.4 \%$ of total energy) were produced from renewable resources, of which $369 \mathrm{Pj}(5.3 \%)$ came from firewood (3.5\%), sugarcane bagasse (1.7\%), and biogas (0.1\%) (SENER 2017).

Forest residues have some advantages over agricultural or second-generation sources for bioenergy generation (Solomon 2010; Pukkala 2018). First, they do not compete for food, as in the case of corn, which in Mexico has been restricted from certain bioenergy programs due to its importance in the Mexican diet (Chuck-Hernández et al. 2011; Pérez-Fernández et al. 2017). Second, they play a critical role in regulating market prices for agricultural crops that otherwise are not used for bioenergy. Corn, sorghum, and wheat are some examples in which their limited use for bioenergy regulates market prices, 
making them affordable for consumers (Pérez-Fernández et al. 2017). Hochman et al. (2014) found that biofuel production has resulted in a $30 \%$ increase in the price of corn during the 2001-2011 period. Third, their relative abundance and low cost, particularly in forest rich areas, reduce total production costs (Alemán-Nava et al. 2015; Ruiz et al. 2016). Depending on the type of species, between $10 \%$ and $22 \%$ of a tree's biomass (Vargas-Larreta et al. 2017) is considered forest residues. However, the extraction of forest residues conveys various issues. Soil nutrient decompensation, soil erosion, and deforestation are undesired consequences if their use do not follow sustainable measures (Perez-Verdin et al. 2012).

There are different methods to estimate forest biomass in forest ecosystems. Direct or destructive methods use felled trees to weight its components (branches, twigs, stems, leaves, etc.) separately (Fonseca et al. 2009). As expected, these methods are expensive, but are more accurate. Non-destructive or indirect methods instead use equations or mathematical models adjusted by means of regression analysis to construct the best relationship between several independent variables, such as diameter at breast height, basal area, volume, or specific density of the wood, and tree biomass. An extension of indirect methods is the use of expansion factors to determine the total dry weight, which can be extrapolated to any similar forest growth conditions (Rojas-García et al. 2015). Remote sensing (e.g., LiDAR technology) is another approach that complements the advantages of indirect methods. These methods can also be combined with parametric and nonparametric statistical methods to get better fitting results. Eventually, these emergent methods allow the estimation of biomass at multiple scales at a larger spatial and temporal coverage (Boudreau et al. 2008).

However, not only is the physical estimation of biomass important, but also the willingness of the owners to extract such products as well as the factors influencing this decision (Joshi et al. 2013). Given that most of the forestlands in Mexico are owned by ejidos, communities or small properties, it is also necessary to identify the social and economic factors that affect the supply of this material. The availability of forest residues is heavily influenced by a landowner's decision to extract the material or not. Many of them fear that the extraction of this material can cause physical damage to the soil and decrease its fertility. Others, however, believe it can be beneficial and that, under certain conditions, it can add and diversify sources of work and reduce the risk of fires. To the authors' knowledge, no single research has been conducted in Mexico to explore the landowners' preferences towards biomass utilization out of forest residues.

This research was conducted in northwestern Durango in a well-organized area that hosts various industries that produce plywood, sawn timber, edge-glued panels, and furniture, among others. The Union of Ejidos, or the aggrupation of several ejidos, is intensively looking to increase the use of forest biomass to produce electricity and heat in their industries. Although the use of forest residues for bioenergy has been steadily increasing in recent years, the vast majority of such residues still remain in the forests or in the yards of forest industries. In the case of forest industries, to avoid the accumulation of by-products, they burn them in open sites with no further use. In the case of branches and tops, they are chopped and scattered on the forest floor to clean the site, reduce risk of fire, retain soil particles, and left to decompose (López-Miranda et al. 2009; Perez-Verdin et al. 2012). While some of the nutrients are either lost to erosion or leached to deeper layers of the forest soil, the remaining part improves soil fertility and water infiltration (Hueso-González et al. 2018), which in turn helps the establishment of new trees, plants.

The overall objective of this research was to present a methodological approach that can be used to analyze the potential use of forest residues as a feedstock to generate bioenergy in Mexico's forests. The approach is comprised of two main goals: (i) to quantify the physical availability of forest residues stocks, through remote sensing and field forest inventory and (ii) to evaluate the most important factors that influence landowners' willingness to extract their products through discrete choice methods. The main reasons to include these two objectives are to make the real availability of feedstocks more comprehensive. It is not enough to know only their physical availability, but the landowners' behavior for both supplying the workforce in harvesting operations and being considered in the decision-making process. Many of them complain that their opinions are never considered in public policies, even though the resource is theirs. In addition, as stated by Joshi et al. (2013), assessing landowners' willingness to participate in a bioenergy project is a relatively new topic in forest economics and policy research. By knowing an expected stumpage price, the combination of these two objectives should pave the road for constructing economic supply curves (e.g., quantity, price) for biomass residues in future studies.

\section{Methods \\ Study area}

Five counties of the northwest region of the state of $\mathrm{Du}$ rango were considered in this appraisal (Fig. 1). Durango is one of the most important forest states in Mexico, contributing about $30 \%$ of timber production nationwide. The average annual rainfall varies from 300 to $1400 \mathrm{~mm}$, while the average annual temperature ranges from $8{ }^{\circ} \mathrm{C}$ to $26^{\circ} \mathrm{C}$. The altitude above sea level ranges 


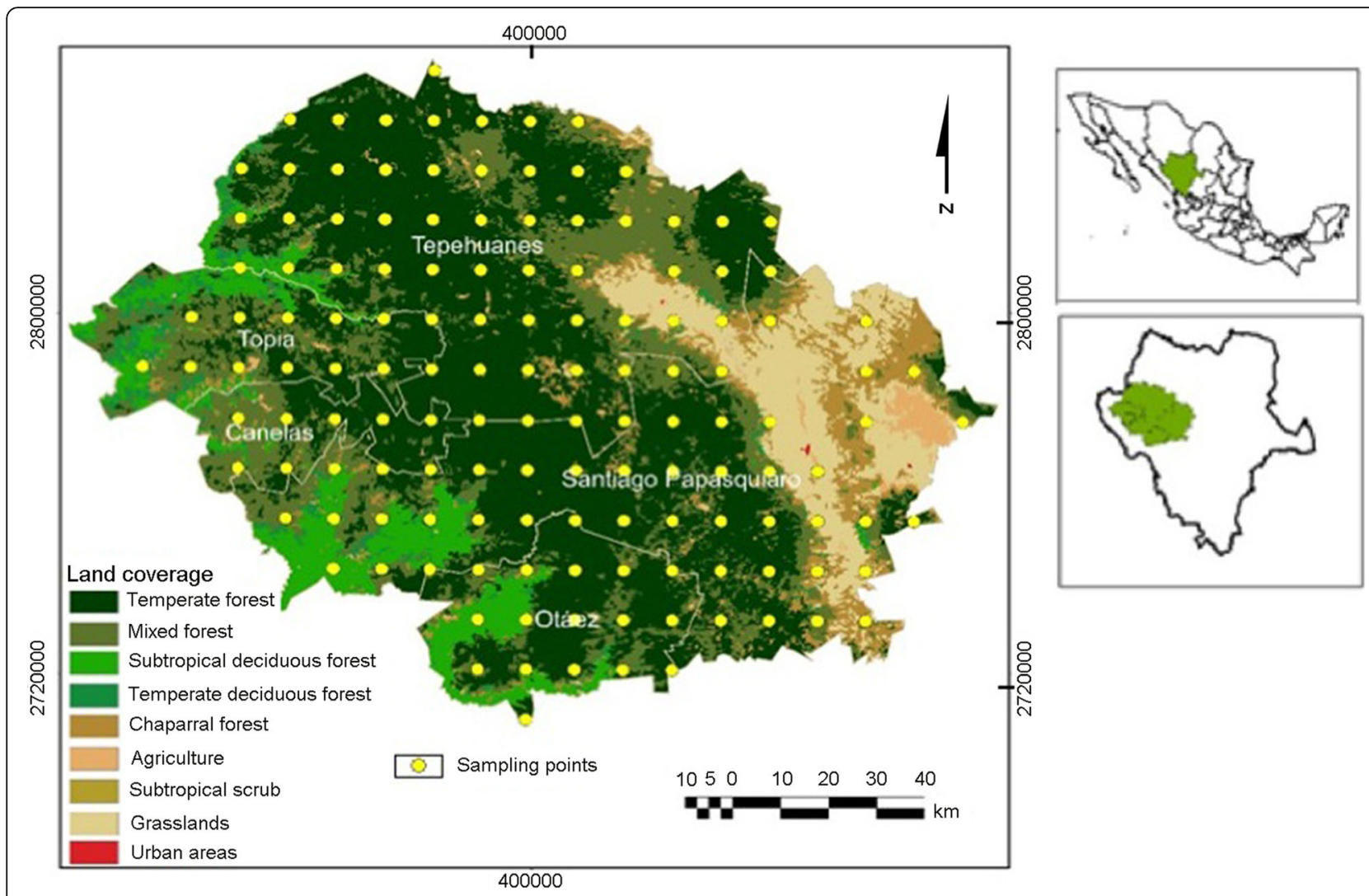

Fig. 1 Location of the study area, biomass sampling points (in yellow), and land coverage types

from 300 to $3200 \mathrm{~m}$. About $84 \%$ of the total area is covered by pine-oak forests, including, among others, Pinus arizonica Engelm., P. engelmanii Martinez, P. strobiformis Engelm., P. durangensis Martinez, P. cooperi C.E. Blanco, P. lumholtzii B.L. Rob., Quercus rugosa Nee, Q. gambelii Nutt., Q. arizonica Sarg., Q. hypoleucoides A. Camus, Arbutus bicolor Gonzalez., and A. madrensis Gonzalez (González-Elizondo et al. 2012).

\section{Tree and stand level biomass estimation}

Tree and stand level biomass were estimated using field data from the 2014 forest inventory, which was provided by the National Forest Commission (CONAFOR), as well as regional biomass equations (Návar 2009; VargasLarreta et al. 2017). The forest inventory included information of tree species, diameter, height, site location coordinates, among others. The forest inventory consisted of a network of $1680400-\mathrm{m}^{2}$ permanent, circular-shaped plots systematically distributed in the area (Fig. 1). The types of forest residues that were considered were tops, twigs, and branches; leaves were excluded from calculations. To avoid a critical soil nutrient decompensation, a minimum load of 1.5 metric tha ${ }^{-1}$ of residues was added to the leaf stock and subtracted from estimations (Sanchez et al. 2003).
Following Návar (2009), an allometric equation that relates tree biomass as a function of normal diameter $(\mathrm{ND})$ was used to estimate tree-level biomass $(A)$.

$$
A_{i}=\beta_{0}(\mathrm{ND})^{\beta_{1}}(1)
$$

where $A_{i}$ is biomass of tree $i(\mathrm{~kg}), \mathrm{ND}$ is normal diameter $(\mathrm{cm}), \beta_{0}$ and $\beta_{1}$ are regression parameters conditional to the type of species. Plot biomass was estimating by adding the biomass of all trees. To standardize units, plot biomass was converted to dry tha ${ }^{-1}$.

\section{Use of remote sensing to estimate the enhanced vegetation index}

Using the United States Geological Service website (USGS 2018), two MODIS satellite images of the Terra sensor were obtained for the months of May and November of 2015. The images were geometrically corrected using the reprojection tools in QGIS $^{\circ}$ (QGIS Development Team 2016). The idea of using two images at different times was to confirm or discard any influence of precipitation on the vegetation. Precipitation in this area occurs from July to September.

In each image, the enhanced vegetation index (EVI) was estimated, which corresponds to an average of 15 
days at a spatial resolution of $250 \mathrm{~m}$ per pixel (product code MOD13Q1). This index is known to include an atmospheric correction in the regions of the electromagnetic spectrum of blue $(400 \mathrm{~nm})$ and red $(700 \mathrm{~m})$ and a correction related to the brightness of the soil (Heute et al. 2002). The values of this index fluctuate between -1 to 1 , where values of -1 to 0 correspond to sites without vegetal coverage. Values of 0 to 1 suggest sites with greater photosynthetic activity or vegetal coverage.

The enhanced vegetation index (EVI) was developed to optimize the vegetation signal with improved sensitivity in high biomass regions and improved vegetation monitoring through a de-coupling of the canopy background signal and a reduction in the atmosphere effects (Heute et al. 2002). According to Heute et al. (2002), the equation to estimate EVI is:

$$
\mathrm{EVI}=G \frac{\mathrm{IRC}-R}{\mathrm{IRC}+C_{1} L R-C_{2} B+L}(2)
$$

where $G$ is a factor for atmospheric correction; this parameter is a simple scale factor and is included only for the complete representation of the original formula. IRC, $R$ and $B$ are surface reflectance values for the near infrared, red, and blue bands, respectively, with a correction of the atmospheric effects. $C_{1}, C_{2}$ are the aerosol resistance coefficients that use the blue band to correct the influence of aerosol in the red band. $L$ is the canopy background setting that takes into account the nearinfrared differential radiant transfer and the red through the canopy.

Once the EVI was estimated, different models and statistical processes were evaluated to determine the best relationship between the EVI (Eq. 2) and the total biomass resulting from Eq. 1. The main reason to relate the EVI with the biomass of forest residues is because there is an appreciable, significant correlation between the two $\left(r^{2}=0.47, p<0.01\right)$. Some authors suggest that areas with higher biomass, reflectance values also increase, eventually leading to higher EVI values (Vargas-Larreta et al. 2017). Thus, a higher total biomass means a greater biomass of forest residues.

\section{Total biomass estimation}

Several linear parametric and automatic learning models were used to estimate total biomass as a function of the EVI. These included the ordinary least squares method and machine learning models. Within machine learning models, random decision forests are perhaps one of the most common methods that allow the classification and regression procedures using a collection of treestructured groups (Breiman 2001; Hastie et al. 2009). Boosting machine is also a popular learning technique for improving the accuracy of any given learning algorithm widely used in computer tasks. Several classifiers are trained sequentially using a weight distribution on labeled samples and additively combined to a strong classifier (Godec et al. 2010).

Ordinary least squares, random forests, and boosting machine models were processed to find the one with the best fit. The selection of the best model was based on the root mean square error and $\mathrm{R}$ squared, in addition to the analysis of residuals. Once the best model was found, maps showing biomass quantity and distribution were prepared. We input the final model into the QGIS ${ }^{\circ}$ algebra tool (QGIS 2016) and calculated the biomass for each pixel of the satellite image. Then, we summed up the number of pixels and quantified total biomass for each county, vegetation type, and the study area. The quantification assumed that only $34 \%$ of the total biomass is usable, which is due to the type of silvicultural treatment applied, and that all the material must be extracted along with commercial timber (or primary products, species), to take advantage of the road network connectivity. The most common silvicultural treatment is the individual selection of trees that removes between $30 \%-40 \%$ of total biomass (UAF 2015). In addition, a 50 -year rotation age was applied, which indicates the number of years between the regeneration of a tree and its final cut (UAF 2015). Forest residues are mostly wet and need to be dried from $30 \%$ to $60 \%$ moisture content to about $8 \%-25 \%$ (Fagernäs et al. 2010; HonoratoSalazar 2017). Because the material would be burned to produce heat or electricity (by combustion), an $8 \%$ of moisture content was used to calculate dry biomass.

\section{Willingness of producers to extract their forest residues}

Due to size, bulk density, and dispersion, the extraction of forest residues require additional costs and, specially, consent from their landowners. An important contribution of this research is the evaluation of landowners' preferences towards the potential use of forest residues for bioenergy (Fig. 2). Due to the land property distribution in Mexico, in which the majority belongs to ejidos (or common properties) and private owners, it is necessary to consider if they would be willing to participate in supplying the raw material. Other studies have focused on the physical estimation of biomass considering factors like forest stocks, spatial distribution, transportation distance, and soil nutrient compensation (Perez-Verdin et al. 2012; Vargas-Larreta et al. 2017). However, the real availability of resources have to weigh the landowners' attitudes and preferences towards the perceived environmental impacts, job generation, and, of course, the price of the raw material if bioenergy is implemented (Gruchy et al. 2012; Joshi et al. 2013; Aguilar et al. 2014).

Following our conceptual model of biomass estimation, a survey was conducted to assess the landowners' 


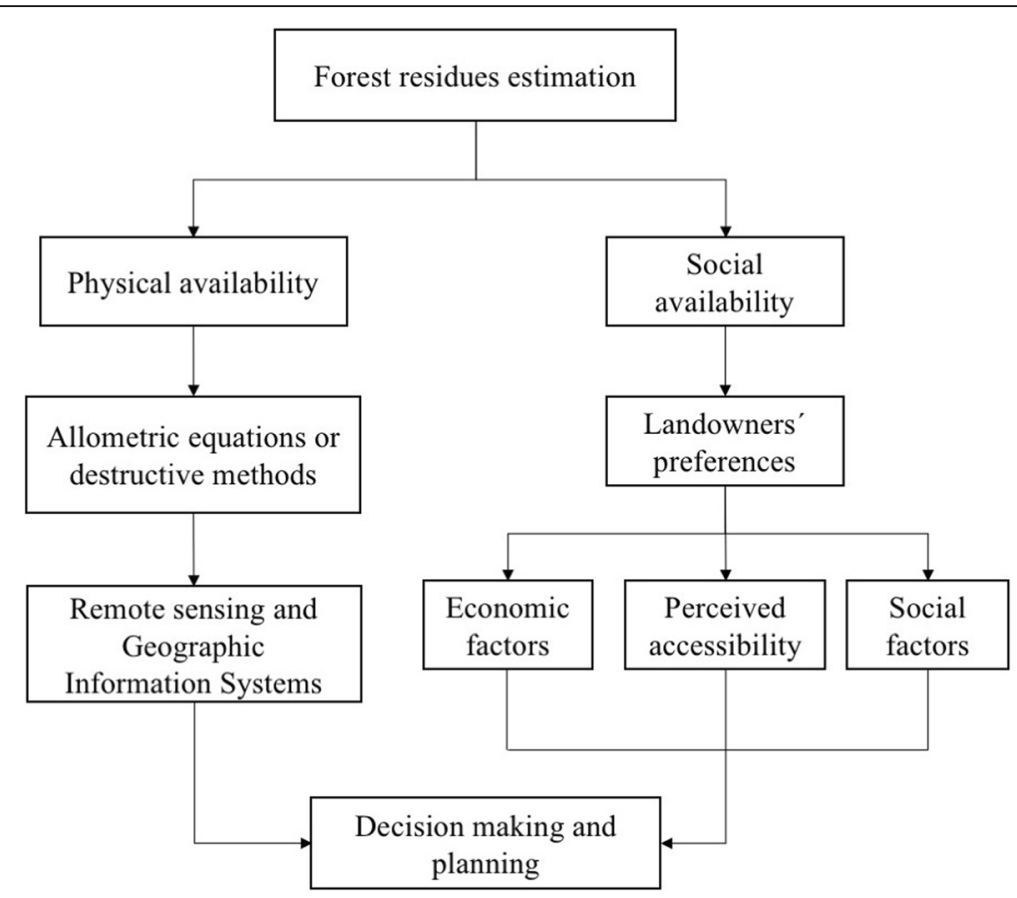

Fig. 2 Conceptual model of the study of the physical and socioeconomic availability of forest residues for bioenergy generation

willingness for extracting their forest residues from their properties (right part of Fig. 2). We used the methodology of choice experiments and designed a questionnaire to find out their preferences in terms of environmental impacts, job generation, accessibility, and other socio-demographic information. The questionnaires were applied to a representative sample of landowners with the support of two forest consulting services units and the Union of Ejidos. This information along with the physical availability of biomass can be useful to design efficient energy policies.

\section{Choice experiments}

Stated-preference methods are increasingly common in environmental research as a way of explaining the most preferred alternatives of respondents (Hjerpe et al. 2015). Two of them are contingent valuation and choice experiments $(\mathrm{CE})$; the latter being increasingly used in recent years for bioenergy studies (Susaeta et al. 2011; Joshi et al. 2013; Bergtold et al. 2014; Khanna et al. 2017). It uses a survey instrument in which participants are asked to choose their preferred alternative from a set of scenarios characterized by different levels of qualitative or quantitative attributes (Horne et al. 2005). A reference alternative that corresponds to the status quo or "do nothing" situation is included. Not only landowners will not be able to obtain any benefit from the supply of raw materials, but they will keep absorbing the cost of their disposal (i.e., chopping, piling, and occasionally burning). Price is always present in the scenarios (or choices) (Hanley et al. 1998). A great advantage of the $\mathrm{CE}$ method over other stated-preference approaches is that besides estimating a value, it is also able to rate, rank, or select an alternative that provides the greatest utility to the respondent (Mogas et al. 2006).

\section{Design and survey management}

The survey was divided into three parts. The first part introduces the concept of bioenergy generated from forest residues and the perceived level of importance of forest resources to provide several ecosystem services. It also asks about their environmental concerns and other forest management statistics. The second part asks respondents to choose the best scenario from an array of options. Given the high number of possible options, usually this part is divided into subsections with two or more set of questions. The third part includes questions about the socio-demographic characteristics of landowners such as age, income, level of education, family size, among others.

Following Rea \& Parker's methodology (1992), for populations smaller than 100,000 people, a sample size was determined considering the percentage of allowed error, level of confidence, and total population size. The study area consisted of 550 properties and covered about 1.6 million hectares, of which 132 ejidos occupy $80 \%$ of the area, while 418 small private properties occupy the rest. We discarded those properties with no current forest management plans, giving a total population of 355 active properties. The rationale behind excluding properties with 
no current plans was to obtain inputs from landowners who would most likely contribute to supply forest residues. Also, one major assumption of this study is that the current road network connectivity serves for both commercial timber and forest residues extraction. Typically, properties with no current forest management plans may need to construct new roads or repair existing ones, which may result in higher production costs.

Considering $\mathrm{a} \pm 10 \%$ of sampling error and a confidence level of $90 \%$, the sample size was calculated at 58 properties. The majority of ejido representatives were men between 26 to 75 years old. Half of them were willing to extract their forest residues if they receive at least MEX\$ 220 per $t$ (US\$ 11 per t) (Table 1). We obtained a list of landowners (or properties) and their spatial location from two forest consulting units. To avoid issues with selection bias, a random selection of landowners was applied. The number of selected properties was weighted according to their proportion between ejidos and private properties.

\section{Levels and attributes of scenarios}

The survey's design and the identification of attributes were based on previous works developed elsewhere (Susaeta et al. 2010; Gruchy et al. 2012; Joshi et al. 2013). Another great advantage of using choice experiment methods is the flexibility of combining qualitative and quantitative attributes. Five attributes were selected with three levels each, plus the original condition. These included: woody biomass utilization, accessibility, environmental impacts, number of jobs, and, as mentioned before, price. Woody biomass utilization is the percentage of biomass that can be removed from the site. Three levels $(85 \%, 40 \%$ and $15 \%)$ were offered to landowners based on conversations with forest managers and landowners as well as on Joshi et al. (2013) and Perlack et al. (2005). Accessibility was labeled as the perceived ability to extract forest residues based on the type of existing

Table 1 Socio-demographic characteristics of the landowners surveyed to evaluate their preferences towards bioenergy development in northwestern Durango, Mexico

\begin{tabular}{ll}
\hline Variable & Sample data \\
\hline Men & $97 \%$ \\
Age range between 26 to 75 years & $91 \%$ \\
Completed elementary school & $35 \%$ \\
Income no greater than MEX 5000 per month & $72 \%$ \\
Accepted a forest residue removal $\leq 40 \%$ & $65 \% *$ \\
Did not accept high environmental impacts & $63 \% *$ \\
Accepted 11 or more jobs generated out of the & $67 \%$ \\
extraction of residues & \\
Accepted a payment of at least MEX\$ 220 per t & $53 \% *$
\end{tabular}

* These data include the status quo choices roads, distance, and topography. This is a typical term known among landowners to refer how hard (or easy) it is to extract timber from a harvesting area. Environmental impacts refer to the perceived effects of biomass removal from the soil (erosion, loss of nutrients), vegetation, and water. While higher biomass removals might increase the likelihood of landowners to extract the raw material, it is true that this scenario could lead to environmental deterioration and reduce soil quality. Both accessibility and environmental impacts took three levels of classification plus the status quo condition. Because of the few sources of employment in the area, the potential to create jobs as a result of biomass extraction was also offered to landowners in three levels: 20, 11 and 5 jobs. Finally, price (or stumpage price) refers to the payment landowners could receive for the right to utilize their forest residues (Grebner et al. 2008). The price levels were based on previous meetings with loggers and landowners who have traded low-dimension trees or branches for charcoal or paper production (Table 2). We hypothesized that higher removal, good accessibility, minimal environmental impacts, more jobs, and higher prices would increase the landowners' willingness to extract the forest residues.

Due to the great number of possible combinations out of the five attributes and three levels, an orthogonal design for the choice scenarios was applied to obtain a representative number of alternatives to be presented to respondents. The orthogonal design is useful for estimating the total effects of the choice attributes, which includes the individual effect of each attribute (Holmes and Adamowicz 2003). Results from the orthogonal design gave 15 scenarios, plus the original condition or status quo (Table 3). Two types of questionnaires were then structured for two groups of respondents (A and B). In each one, two packages of scenarios (plus the original condition) were proposed, scenarios from 1 to 8 being in option $A$ and scenarios from 9 to 15 in option B. A total of 58 ejidos, communities, and private properties were surveyed: 31 had questionnaire type A and 27 had type B. Our design resulted in 205 responses.

\section{Random utility theory}

The theoretical basis for using the choice experiment (CE) method is derived from the random utility model (Holmes and Adamowicz 2003). Landowners $(n=1, \ldots, \mathrm{N})$ maximize the value of their forests by comparing $\mathrm{J}$ forest extraction alternatives $(j=1, \ldots, \mathrm{J})$ and selecting the one that provides the highest level of satisfaction or utility. The economic rationality suggests that a landowner prefers an alternative to extract forest residues if its indirect utility increases more than the other alternatives available (Joshi et al. 2013). The random utility model assumes that the 
Table 2 Levels and attributes used in the scenarios to assess the socio-economic availability of forest residues

\begin{tabular}{|c|c|c|c|c|c|}
\hline Attributes & Description & Levels & & & Status quo \\
\hline $\begin{array}{l}\text { Woody biomass utilization } \\
(\%)\end{array}$ & $\begin{array}{l}\text { The percentage of total residues that will be removed from the } \\
\text { site. }\end{array}$ & 85 & 40 & 15 & 0 \\
\hline $\begin{array}{l}\text { Perceived accessibility } \\
\text { (numeric code) }\end{array}$ & $\begin{array}{l}\text { The perceived ability to extract forest residues based on roads, } \\
\text { distance, and topography. }\end{array}$ & Good (2) & $\begin{array}{l}\text { Reduced } \\
(-1)\end{array}$ & $\begin{array}{l}\text { Medium } \\
\text { (1) }\end{array}$ & $\begin{array}{l}\text { Original } \\
(0)\end{array}$ \\
\hline $\begin{array}{l}\text { Environmental impact } \\
\text { (numeric code) }\end{array}$ & Perceived impacts to soil quality, water quality, and biodiversity. & $\begin{array}{l}\text { High } \\
(-1)\end{array}$ & Medium (1) & Little (2) & None $(0)$ \\
\hline Number of jobs & $\begin{array}{l}\text { Potential jobs created as a result of the extraction of forest } \\
\text { residues. }\end{array}$ & 20 & 11 & 5 & 0 \\
\hline Price (MEX\$ per t) & $\begin{array}{l}\text { The amount of MEX\$ per } t \text { that will be paid to landowners } \\
\text { (stumpage price). }\end{array}$ & $\$ 220$ & $\$ 110$ & $\$ 40$ & $\$ 0$ \\
\hline
\end{tabular}

indirect utility of an individual is the sum of a set of known variables during the investigation and a stochastic element (not known for the researcher). This model is defined as (McFadden 1973):

$$
U_{i j}=V_{i j}+\varepsilon_{i j}
$$

where $U_{i j}$ is the utility of landowner $n$ from choosing between different alternatives $j ; V_{i j}$ is the determinist part of the utility, and $\varepsilon_{i j}$ reflects a set of unobservable factors linked to the respondent's choice.

Out of all the choices, the individual chooses alternative $j$, which reflects a change or improvement, over alternative $k$ (status quo) if the utility associated with alternative $j$ exceeds the utility of alternative $k$ (Holmes and Adamowicz 2003). The probability that the individual chooses alternative $j$ over $k$ is:

$$
P_{n j}=P\left(V_{n j}+\varepsilon_{n j}\right)>P\left(V_{n k}+\varepsilon_{n k}\right), j \neq k
$$

If the stochastic term $\varepsilon_{n j}$ is independent, with an extreme value distribution, eq. 4 becomes a conditional logistic model (Train 2003), where the probability that a landowner $n$ chooses scenario $j$ is:

$$
P_{n j}=\frac{e^{V_{n k}}}{\sum_{j} e^{V_{n j}}}
$$

The questionnaires were conducted from December 2017 to February 2018. All were taken through face-toface interviews, first asking if they were willing to participate in the survey, then introducing the objectives of the study and making sure that the respondent under-

\begin{tabular}{|c|c|c|c|c|c|}
\hline Scenario & Removal (\%) & Accessibility & Impact & Number of Jobs & Price $\left(\right.$ MEX $\left.\$ \cdot t^{-1}\right)$ \\
\hline 1 & 85 & Good & High & 20 & 220 \\
\hline 2 & 15 & Good & Medium & 20 & 40 \\
\hline 3 & 85 & Bad & Little & 20 & 220 \\
\hline 4 & 85 & Good & High & 5 & 110 \\
\hline 5 & 85 & Regular & Little & 5 & 40 \\
\hline 6 & 15 & Bad & High & 5 & 220 \\
\hline 7 & 40 & Good & Little & 11 & 220 \\
\hline 8 & 85 & Regular & Medium & 20 & 220 \\
\hline 9 & 40 & Regular & High & 20 & 110 \\
\hline 10 & 85 & Good & High & 11 & 40 \\
\hline 11 & 85 & Bad & Medium & 11 & 110 \\
\hline 12 & 15 & Good & Little & 20 & 110 \\
\hline 13 & 40 & Bad & High & 20 & 40 \\
\hline 14 & 15 & Regular & High & 11 & 220 \\
\hline 15 & 40 & Good & Medium & 5 & 220 \\
\hline 16 & 0 & Original & None & 0 & 0 \\
\hline
\end{tabular}
stood each question. The interviews were held in the

Table 3 List of selected scenarios resulting from the orthogonal design 
Table 4 Parameter used to select the best model to predict biomass as a function of the EVI

\begin{tabular}{llll}
\hline Parameter & Linear regression & Random Forest & Boosting machine \\
\hline Average $\left(\mathrm{t} \cdot \mathrm{ha}^{-1}\right)$ & 8.336 & 8.3298 & 8.1521 \\
Standard deviation & 2.182 & 2.814 & 2.113 \\
$R^{2}$ & 0.226 & 0.231 & 0.285 \\
Root mean square error & 3.602 & 3.872 & 4.03 \\
\hline
\end{tabular}

Unión de Ejidos, in the community of Torance, or directly in their property.

\section{Results}

Results of the three biomass models (ordinary least squares, random forests, and boosting machine), as a function of the EVI vegetation index, showed that the best one was the linear regression model (Table 4). Though the linear model had a slightly lower, but statistically significant $(p<0.05), \mathrm{R}$ square, its root mean square error was the lowest. Given also that the linear model can generate an equation, which the other two cannot, and considering the easiness of application, we decided to use it to eventually calculate the total biomass in the study area. Table 5 shows the analysis of variance of the linear model and the values of its regression coefficients. Both coefficients were statistically significant.

Using the coefficients of the variables (Table 5), we input their values into the QGIS raster calculator and calculated the biomass at a pixel level of the satellite image. Figure 3 shows the concentrations of biomass ranging from $3.8 \mathrm{t} \cdot \mathrm{ha}^{-1}$ in the eastern part to $25 \mathrm{t} \cdot \mathrm{ha}^{-1}$ in the western part. In total, the study area may be producing around 70,699 dry ton of biomass annually.

\section{Landowners' perceptions}

Close to $84 \%$ of respondents are willing to extract their forest residues. The most preferred scenario was the status quo with $16 \%$ of choices, followed by the plans: 3 (12\%), 12 (10\%), and 1 (9.7\%). The least preferred scenarios were 4 and 11 , with only one selection. Overall, $53 \%$ are willing to extract forest residues if they receive at least MEX\$220 per $\mathrm{t}, 18 \%$ if they receive $\$ 110$ per $\mathrm{t}$, and $12 \%$ if they receive $\$ 40$ per $t$. As for the logistic regression analysis, four variables were statistically significant. The probability of extracting their forest residues increases when the perceived environmental impact is lower and more jobs are created. It reduces when the percentage of residues removal increases. As expected,

Table 5 Analysis of variance of the linear regression model $(n=1211)$

\begin{tabular}{lllll}
\hline & Coefficients & Standard error & $t$ value & Probability \\
\hline Interception & -2.263 & 0.574 & -3.948 & $8.66 \mathrm{E}-05$ \\
$\mathrm{EVI}$ & 44.094 & 2.344 & 18.83 & $1.41 \mathrm{E}-69$ \\
\hline
\end{tabular}

the probability increases as the stumpage price (or the price paid to the owner for the right to extract the forest residues) also increases (Table 6).

\section{Discussion}

Temperate forests showed the highest values of forest residues (around $25.3 \mathrm{t} \cdot \mathrm{ha}^{-1}$ ). This type of forests consists of Pinus, Quercus, Cupressus, and other broadleaf species. Low values of biomass (around $3.8 \mathrm{t}^{\circ} \mathrm{ha}^{-1}$ ) were found in the shrub and grasslands areas. Some shrub areas and deciduous trees have the appearance of a dry forest (Lopez and Ramirez 2004). This characteristic, and the date on which the image was taken (May 2015), could be factors that explain the low amount of solar light reflected, low EVI values, and, eventually, available biomass. The results of the satellite image taken in November had a worse performance than the one of May; so the analysis for this month was discarded. Many deciduous trees start dropping their leaves as early as October (González-Elizondo et al. 2007), which seems to explain its bad performance.

Results showed that, on average, $8.3 \mathrm{dry} \mathrm{t} \cdot \mathrm{ha}^{-1}$ of forest residues are found in the study area (confidence interval between 4.05 to $12.61 \mathrm{t}^{-\mathrm{ha}^{-1}}$ ). Vargas-Larreta et al. (2017) found, in a larger scale study, between 9.5 and $19.5 \mathrm{t} \cdot \mathrm{ha}^{-1}$, considering a proportion of $14.9 \%$ of forest residues over the total above-ground biomass. These results are slightly higher than the ones estimated in our investigation. The differences are perhaps due to the type of methods or databases used. They considered a different network of permanent plots and their estimations were based on machine learning models. However, it is agreed that the EVI is an adequate approach for estimating biomass. Other authors have reported biomass estimates using the Geographic Information Systems (GIS) and allometric equations. Using a set of regional allometric equations, national forest inventory database, and forest management programs, Perez-Verdin et al. (2012) found in this area about 78,000 t per year, which is pretty close to the numbers estimated in our study (before considering the socio-economic analysis).

\section{Landowners' willingness to extract their forest residues}

As remarked throughout this research, biomass availability should consider the landowners' preferences to extract this type of material. This study found that close to 


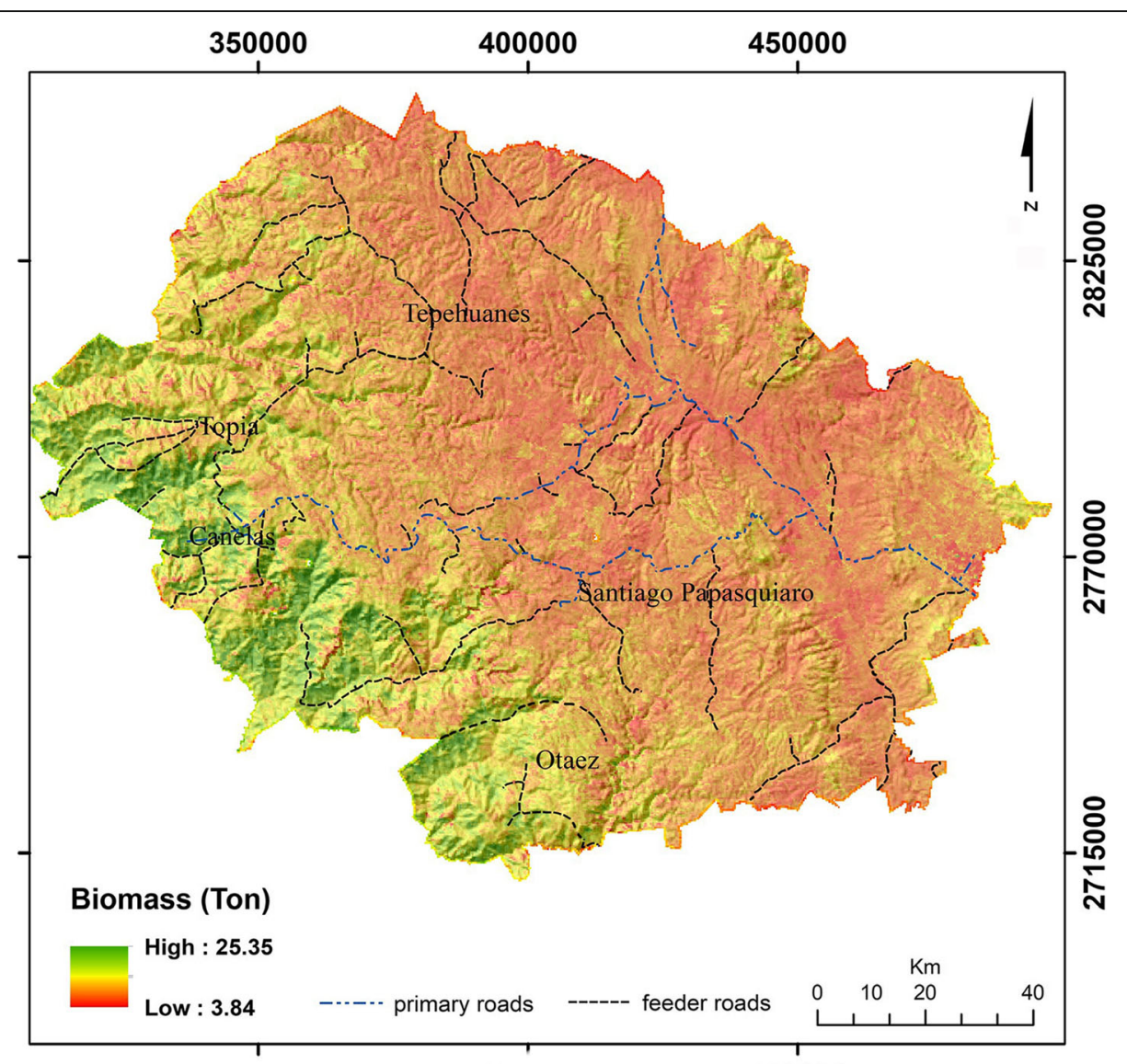

Fig. 3 Biomass distribution using the enhanced vegetation index (EVI) in northwestern Durango, Mexico

$84 \%$ of respondents are willing to extract their forest residues. This means that 59,300 dry t.year ${ }^{-1}$ would be physically and socially available to use. Furthermore, considering the stumpage price and the number of landowners who are supposed to supply this material, about $36,000 \mathrm{t}$ per year are available at MEX\$ 220 per $\mathrm{t}$ (US\$ 11 per $\mathrm{t}$ ), $14,100 \mathrm{t}$ per year at MEX $\$ 110$ (US\$ 5.5 per $\mathrm{t}$ ), and $8480 \mathrm{t}$ per year at MEX\$ 40 per $\mathrm{t}$ (US\$ 2 per $\mathrm{t}$ ). These results show the implications of considering the landowners opinions in the estimation of biomass

Table 6 Conditional logistic parameter estimates of landowners' preferences for supplying forest residues for bioenergy in northern Mexico

\begin{tabular}{lllllll}
\hline Variable & Coef. & $\begin{array}{l}\text { Std. } \\
\text { Err. }\end{array}$ & & $p>|z|$ & \multicolumn{2}{c}{$95 \%$ Conf. interval } \\
\cline { 6 - 7 } & & & & & Min & Max \\
\hline Removal & -0.012 & 0.003 & -4.030 & 0.000 & -0.017 & -0.006 \\
Accessibility & 0.075 & 0.084 & 0.900 & 0.369 & -0.089 & 0.239 \\
Impact & 0.177 & 0.084 & 2.120 & 0.034 & 0.014 & 0.341 \\
Jobs & 0.035 & 0.014 & 2.520 & 0.012 & 0.008 & 0.063 \\
Price & 0.004 & 0.001 & 5.680 & 0.000 & 0.003 & 0.005 \\
\hline
\end{tabular}

Log likelihood $=-188.4 ;$ Pseudo $R^{2}=0.19 ;$ Model significance $\left(\right.$ Prob $\left.>X^{2}\right)<0.01$ feedstocks. By virtue of the type of land ownership in Mexico, in which different degrees of responsibility were transferred to local communities, this type of analysis can help delineate efficient wood-based bioenergy policies according to the landowners' needs and aspirations. It not only shows the proportion of landowners willing to participate in potential bioenergy projects, but also the factors motivating such decision. In addition, it could pave the road to construct real supply curves for forest residues. Obviously, other costs such as transportation and processing operations have to be considered. Even though this material can be considered as waste, any bioenergy policy, whose feedstock base is from forest residues, should consider a stumpage price to landowners.

Results showed that more than half of respondents (53\%) are willing to extract their forest residues with the highest possible payment. The expectation of having the highest payment may be because the majority (72\%) earns a monthly income between MEX\$ 2000 and \$ 6000 (US\$ 100-300), and this type of alternative is seen with great interest. The sociodemographic variables and their interactions with the attributes were not significant for this study; the sample was, in general, a very homogeneous group. 
Choosing a scenario different to the status quo is not surprising. A scenario that could generate better living conditions is better than not having this type of extra income opportunities. What is a little surprising is that many landowners (63\%), while giving enough importance to the economic benefits, showed some concerns about the environmental impacts this activity could have on the soil, plants, and fauna. These seemingly conflicting interests have been also reported by Joshi et al. (2013). They found that some landowners prefer forest scenarios that provide them an optimum premium with a minimal loss of environmental quality. These results could lead to subsequent studies focusing on reducing environmental impacts if bioenergy from forest biomass is implemented.

Soliño-Millán et al. (2008) evaluated the role of a bioenergy program based on the partial replacement of electricity generated from fossil fuels for electricity generated from forest biomass in Galicia, Spain. They too applied the method of choice experiments. Their results showed that, like in this study, people are willing to accept compensation as long as they get the most expensive options. The results of these investigations also reveal the need to create awareness and provide training to increase the knowledge of owners about the extraction of wood, the use of forest biomass, and ecological sustainability.

\section{Conclusions}

This study estimated the physical and socio-economic availability of forest residues to be used as a feedstock for bioenergy conversion in northern Mexico. The study used information from allometric equations for several tree species, satellite images, CONAFOR's forest inventory, and landowners' perceptions. It is concluded that in the study area, about 59,000 t per year of forest residues can be physically and socio-economically available. The availability varies according to the expected price. It also showed that the most preferred scenario, out of the 16 presented to landowners, was the status quo. This means that for many of them doing nothing seems to be the best deal. For those landowners who agreed with the extraction of forest residues, the majority is willing to do so as long as they are presented with extraction plans with the highest stumpage price and, at the same time, the lowest environmental impact. The results of this research provide important information on landowners' preferences on forest residue extraction generated during timber harvesting operations. Their concern over possible adverse environmental impacts and their willingness to invest in the extraction activities to take advantage of this material is evident.

The use of forest residues for bioenergy represent a market opportunity and an important source of employment in rural areas. It can help boost the local economies, reduce risk of fire, and eventually reduce fossil fuel dependency. However, given that this is a relatively new issue for Mexico's landowners, awareness must be raised about the benefits and implications obtained by collecting this resource. Likewise, more research is needed to improve biomass estimation through remote sensing and to better understand landowner's behavior through more refined socio-economic valuation methods.

\section{Acknowledgements \\ We would like to thank CONAFOR for allowing us to use the Forest Inventory database. Many thanks to the landowners who participated in the surveys, as well as the forest consulting units of Santiago Papasquiaro and Topia.}

Ethical approval and consent to participate

All procedures performed in studies involving human participants were in accordance with the ethical standards of the Instituto Politecnico Nacional or comparable ethical standards.

\section{Authors' contributions}

GCD conducted field data collection, data analysis, and wrote the manuscript. GPV coordinated the research project, made statistical analysis, and wrote the manuscript. JEF and MAML carried out the spatial analysis and wrote the manuscript. All authors read and approved the final manyscript.

\section{Funding}

This research received funds from IPN, SIP 2018-0860, CONACYT, and COCYTED.

Availability of data and materials

Data are available from the corresponding author on reasonable request.

Consent for publication

Not applicable.

\section{Competing interests}

The authors declare that they have no competing interests.

Received: 7 January 2019 Accepted: 11 September 2019

Published online: 19 October 2019

\section{References}

Aguilar FX, Cai Z, Amato AWD (2014) Non-industrial private forest owner's willingness- to-harvest: how higher timber prices influence woody biomass supply. Biomass Bioenergy 71:202-215. https://doi.org/10.1016/j.biombioe. 2014.10.006

Alemán-Nava GS, Meneses-Jacome A, Cardenas-Chavez DL, Diaz-Chavez R, Scarlat N, Dallemand JF, Ornelas-Soto N, Garcia-Arrazola R, Parra R (2015) Bioenergy in Mexico: status and perspective. Biofuels Bioprod Biorefin 9:8-20. https:// doi.org/10.1002/bbb.1523

Bergtold JS, Fewell J, Williams J (2014) Farmers' willingness to produce alternative cellulosic biofuel feedstocks under contract in Kansas using stated choice experiments. Bioen Res 7:876-884. https://doi.org/10.1007/s12155-014-9425-9

Boudreau J, Nelson RF, Margolis HA, Beaudoin A, Guindon L, Kimes DS (2008) Regional aboveground forest biomass using airborne and spaceborne LiDAR in Québec. Remote Sens Environ 112:3876-3890. doi: https://doi.org/10.1016/ j.rse.2008.06.003

Breiman L (2001) Random forests. Mach Learn 45:5-32. https://doi.org/10.1023/a: 1010933404324

Chuck-Hernández C, Pérez-Carrillo E, Heredia-Olea E, Serna-Saldívar SO (2011) Sorgo como un cultivo multifacético para la producción de bioetanol en México: Tecnologías, avances y áreas de oportunidad. Revista mexicana de ingeniería química 10:529-549

Fagernäs L, Brammer J, Wilén C, Lauer M, Verhoeff F (2010) Drying of biomass for second generation synfuel production. Biomass Bioenergy 34:1267-1277. https://doi.org/10.1016/j.biombioe.2010.04.005 
Fonseca GW, Alice F, Rey JM (2009) Modelos para estimar la biomasa de especies nativas en plantaciones y bosques secundarios en la zona Caribe de Costa Rica. Bosque 30:36-47. https://doi.org/10.4067/S0717-92002009000100006

Fraver S, Ducey MJ, Woodall CW, D'Amato AW, Milo AM, Palik BJ (2018) Influence of transect length and downed woody debris abundance on precision of the line-intersect sampling method. For Ecosyst 5:39. https://doi.org/10.1186/ s40663-018-0156-9

Godec M, Grabner H, Leistner C (2010) Speeding up semi-supervised on-line boosting for tracking. https://www.researchgate.net/profile/Horst_Bischof/ publication/228818733_Speeding_Up_Semi-Supervised_On-line_Boosting_ for_Tracking/links/Ofcfd51113a955290e000000/Speeding-Up-Semi-SupervisedOn-line-Boosting-for-Tracking.pdf.

González-Elizondo MS, González-Elizondo M, Márquez-Linares MA (2007) Vegetación y ecorregiones de Durango. Plaza y Valdés Editores-Instituto Politécnico Nacional. Mexico, D.F

González-Elizondo MS, González-Elizondo M, Tena-Flores JA, Ruacho-González L, López-Enríquez I (2012) Vegetación de la sierra madre occidental, México: Una síntesis. Acta Bot Mexic 100:351-404

Grebner DL, Perez-Verdin G, Sun C, Munn IA, Schultz EB, Matney TG (2008) Woody biomass feedstock availability, production costs and implications for bioenergy conversion in Mississippi. Renewable Energy from Forest Resources in the United States. https://doi.org/10.4324/9780203888421

Gruchy SR, Grebner DL, Munn IA, Joshi O, Hussain A (2012) An assessment of nonindustrial private forest landowner willingness to harvest woody biomass in support of bioenergy production in Mississippi: a contingent rating approach. Forest Policy Econom 15:140-145. https://doi.org/10.1016/j.forpol. 2011.09.007

Hanley N, Wright RE, Adamowicz V (1998) Using choice experiments to value the environment: design issues, current experience and future prospects. Environ Res Econ 11:413-428

Hastie T, Tibshirani R, Friedmand J (2009) The elements of statistical learning: data mining, inference, and prediction. Springer, Second Edition

Heute A, Didan K, Miura T, Rodriguez EP, Gao X, Ferreira LG (2002) Overview of the radiometric performance of the MODIS vegetation indices. Remot Sens Environ 83:195-213

Hjerpe E, Hussain A, Phillips S (2015) Valuing type and scope of ecosystem conservation: a meta-analysis. J Forest Econom 21:32-50. https://doi.org/10. 1016/j.jfe.2014.12.001

Hochman G, Rajagopal D, Timilsina G, Zilberman D (2014) Quantifying the causes of the global food commodity price crisis. Biomass Bioenergy 68:106-114 https://doi.org/10.1016/j.biombioe.2014.06.012

Holmes TP, Adamowicz WL (2003) Attribute-based methods. In: Champ PA, Boyle $\mathrm{KJ}$, Brown TC (eds) A primer on nonmarket valuation Kluger academic publishers. Norwell, MA, pp 171-219

Honorato-Salazar JA (2017) Caracterizacion fisico-quimica de materiales lignocelulósicos. Fondo sectorial SENER-CONACYT Sustentabilidad Energética. INIFAP, Puebla, Pueb, p 60

Horne P, Boxall PC, Adamowicz WL (2005) Multiple-use management of forest recreation sites: a spatially explicit choice experiment. Forest Ecol Manag 207: 189-199. https://doi.org/10.1016/j.foreco.2004.10.026

Hueso-González P, Martínez-Murillo JF, Ruiz-Sinoga JD (2018) Benefits of adding forestry clearance residues for the soil and vegetation of a Mediterranean mountain forest. Sci Total Environ 615:796-804. https://doi.org/10.1016/j. scitotenv.2017.09.301

Joshi O, Grebner DL, Munn IA, Hussain A, Gruchy SR (2013) Understanding landowner preferences for woody biomass harvesting: a choice experimentbased approach. For Sci 59:549-558

Khanna M, Louviere J, Yang X (2017) Motivations to grow energy crops: the role of crop and contract attributes. Agric Econom (UK) 48:263-277. https://doi. org/10.1111/agec.12332

Lopez MJ, Ramirez N (2004) Composición florística y abundancia de las especies en un remanente de bosque deciduo secundario. Acta Biol Venez 24(2):29-71

López-Miranda J, Soto-Cruz NO, Rutiaga-Quiñones OM, Medrano-Roldán H, Arévalo-Niño K (2009) Optimización del proceso de obtención enzimática de azúcares fermentables a partir de aserrín de pino. Rev Int Contam Ambient 25:95-102

McFadden D (1973) Conditional logit analysis of qualitative choice behavior. Front Econom:105-142. https://doi.org/10.1108/eb028592

Mogas J, Riera P, Bennett J (2006) A comparison of contingent valuation and choice modelling with second-order interactions. J Forest Econom 12:5-30. https://doi.org/10.1016/j.jfe.2005.11.001
Návar J (2009) Allometric equations for tree species and carbon stocks for forests of northwestern Mexico. For Ecol Manag 257:427-434. https://doi.org/10. 1016/j.foreco.2008.09.028

Ngugi MR, Neldner VJ, Ryan S, Lewis T, Li JR, Norman P, Mogilski M (2018) Estimating potential harvestable biomass for bioenergy from sustainably managed private native forests in Southeast Queensland, Australia. For Ecosyst 5:6. https://doi.org/10.1186/s40663-018-0129-z

Pérez-Fernández A, Rivas-Martínez MI, Caamal-Cauich I, Martínez-Luis D (2017) La producción de bioetanol y su impacto en el precio de productos agrícolas en México. Ecosistemas y Recursos Agropecuarios 4:597-602

Perez-Verdin G, Navar-Chaidez JJ, Grebner DL, Soto-Alvarez CE (2012) Disponibilidad y costos de producción de biomasa forestal como materia prima para la producción de bioetanol. Forest Systems 21:526-537. doi: https://doi.org/10.5424/fs/2012213-02636

Perlack RD, Wright LL, Turhollow AF, Graham RL (2005) Biomass as feedstock for a bioenergy and bioproducts industry: the technical feasibility of a billion-ton annual supply. U.S. Department of Energy, Oak Ridge, TN

Pukkala T (2018) Carbon forestry is surprising. For Ecosyst 5:11. https://doi.org/10. $1186 /$ s40663-018-0131-5

QGIS (2016) Quantum geographic information system. Open Source Geospatial Foundation Project. http://qgis.osgeo.org.

Rodriguez-Soalleiro R, Eimil-Fraga C, Gomez-Garcia E, Garcia-Villabrille JD, RojoAlboreca A, Munoz F, Oliveira N, Sixto H, Perez-Cruzado C (2018) Exploring the factors affecting carbon and nutrient concentrations in tree biomass components in natural forests, forest plantations and short rotation forestry. For Ecosyst 5:35. https://doi.org/10.1186/s40663-018-0154-y

Rojas-García F, De Jong BHJ, Martínez-Zurimendí P, Paz-Pellat F (2015) Database of 478 allometric equations to estimate biomass for Mexican trees and forests. Ann Forest Sci 72:835-864. https://doi.org/10.1007/s13595-015-0456-y

Ruiz HA, Martínez A, Vermerris W (2016) Bioenergy potential, energy crops, and biofuel production in Mexico. Bioen Res 9:981-984. https://doi.org/10.1007/ s12155-016-9802-7

Sanchez FG, Carter EA, Klepac JF (2003) Enhancing the soil organic matter pool through biomass incorporation. Biomass Bioenergy 24:13

Schlegel B, Gayoso J, Guerra J (2000) Manual de procedimientos muestreos de biomasa forestal. Universidad Austral De Chile, Chile

SENER (2017) Balance Nacional de Energia. Secretaria de Energía (SENER) https:// www.gob.mx/cms/uploads/attachment/file/414843/Balance_Nacional_de_ Energ_a_2017.pdf.

Soliño-Millán M, Vázquez-Rodríguez M, Prada-Blanco A (2008) Consistencia en experimentos de elección: aplicación a la valorización eléctrica de la biomasa forestal en España. http://wwwuibcongresorg/imgdb/archivo_dpo4091pdf Assessed 07 Jan 2019

Solomon BD (2010) Biofuels and sustainability. Ann N Y Acad Sci 1185:119-134. https://doi.org/10.1111/j.1749-6632.2009.05279.x

Susaeta A, Alavalapati J, Mercer E (2010) Assessing public preferences for forest biomass based energy in the southern United States. Environ Manag 45:697710. https://doi.org/10.1007/s00267-010-9445-y

Susaeta A, Lal P, Alavalapati J, Mercer E (2011) Random preferences towards bioenergy environmental externalities: a case study of woody biomass based electricity in the southern United States. Energy Econom 33:1111-1118. https://doi.org/10.1016/j.eneco.2011.05.015

UAF (2015) Estudio De Cuenca De Abasto Umafores 1004 Topia-Canelas Y 1005 Santiago Papasquiaro, Dgo. Unidad de Admnistracion Forestal Santiago Papasquiaro

USGS (2018) United States Geological Service Global Visualization Viewer (GloVis). https://glovis.usgs.gov/.

Vargas-Larreta B, López-Sánchez CA, Corral-Rivas JJ, López-Martínez JO, AguirreCalderón CG, Álvarez-González JG (2017) Allometric equations for estimating biomass and carbon stocks in the temperate forests of North- Western Mexico. Forests. https://doi.org/10.3390/f8080269

Yuan JS, Tiller KH, Al-Ahmad H, Stewart NR, Stewart CN (2008) Plants to power: bioenergy to fuel the future. Trend Plant Sci 13:421-429. https://doi.org/10. 1016/j.tplants.2008.06.001

Zhu XG, Long SP, Ort DR (2008) What is the maximum efficiency with which photosynthesis can convert solar energy into biomass? Curr Opin Biotechnol 19:153-159. https://doi.org/10.1016/j.copbio.2008.02.004 